\title{
Effects on blood coagulation, fibrinolysis, and platele aggregation of normal and atheromatous aortic tissue
}

\author{
C. R. M. PRENTICE, G. P. McNiCOL, AND A. S. DOUGLAS \\ From the University Department of Medicine, Glasgow Royal Infirmary
}

SYNOPSIS A comparison was made between the effects of atheromatous and normal areas of the same aorta on coagulation, fibrinolytic, and platelet aggregating systems.

In the thromboplastin generation test it was found that atheromatous aorta possessed significantl greater ability to generate intrinsic prothrombin activator than did normal aortic tissue. But, bみ the one-stage prothrombin time technique, the content of extrinsic thromboplastin in both types of aorta was similar.

Aortic preparations, consisting of intimal and medial layers only, were not found to posses $\vec{s}$ fibrinolytic ability and did not contain inhibitors of the fibrinolytic system.

The adhesion of platelets to ulcerated atheromatous areas of aorta was significantly greater thaô to normal or non-ulcerated atheromatous areas. However, homogenates of atheromatous an normal aorta did not differ in their ability to accelerate platelet aggregation and fibrin clot forms ation when tested by a modified Chandler's tube technique.

The significance of the findings is discussed and the suggestion made that the mechanisms b which atheromatous aortic tissue might predispose towards intravascular thrombosis in vivo areे the ability of such tissue to enhance intrinsic prothrombin activator formation and platelet aggres gation.

Three possible mechanisms whereby thrombus may be formed in association with atheromatous arterial lesions include exposure of the blood to thromboplastic activity, accelerated aggregation of platelets, or local inhibition of fibrinolytic activity. Accordingly, it was thought worth while to study the thromboplastic, antifibrinolytic, and platelet aggregating properties of normal and atheromatous aorta.

Existing evidence suggests that arterial wall has poor fibrinolytic but moderate coagulative activity. Several studies have shown that blood vessels possess tissue or extrinsic thromboplastic activity (Astrup, Albrechtsen, Claassens, and Rasmussen, 1959; Kirk, 1960; Donner, 1962), although this was present in equal or greater concentrations in normal compared with atheromatous artery. Stevenson, Schrodt, and Reed (1961) found that the generation of intrinsic, i.e., blood, thromboplastin by atheromatous artery was greater than that of normal vessel. Platelet aggregating substances identified as adenosine diphosphate (Mitchell and Sharp, 1964) and collagen-like (Zucker and Borrelli, 1962) have been extracted from arterial wall.

Received for publication 11 August 1965.
The fibrinolytic enzyme system, which is comple has four main components: plasminogen, plasmin. activators, and inhibitors. Plasminogen, an ine plasma globulin, is converted by activators to plasmin, a proteolytic enzyme which under physio logical circumstances is restricted to fibrinogen as substrate. Activators of plasminogen include tissue activators, a plasma activator, and a urinarø activator named urokinase. Fibrinolytic activity presumably due to tissue activator, has been foun $\mathbf{q}$ to be confined to the arterial adventitial laye (Astrup et al., 1959), although Todd (1964) and Warren (1964) found small amounts within three vascular endothelium.

The present study was designed to assess the pat played by the normal and atheromatous vessel waif in the formation of intravascular thrombi. A com parison between the two types of vessel was made by the assay of intrinsic (blood) and extrinsig (tissue) prothrombin activator content, antifibrinos lytic activity, and platelet-aggregating ability.

$$
\text { METHODS }
$$

Aortic tissue was taken at necropsy from 11 patients 
aged between 28 and 86 years, within 24 hours of death. In no case had there been a previous haemorrhagic disorder and none had been given anticoagulant therapy. Thoracic aorta was isolated, stripped of peri-adventitial tissue, and the adventitial layer was dissected off and discarded. From each aorta, an area of uncomplicated atheromatous plaques (W.H.O. classification, grade II) and an area of macroscopically normal tissue was selected and excised. Two gram portions of tissue, consisting of intimal and medial layers, were taken from both normal and atheromatous areas, washed free of blood, and chopped into small pieces. Each was then homogenized at room temperature in a Quickfit homogenizer with $8 \mathrm{ml}$. $0.85 \%$ saline for 15 to 30 minutes until a creamy granular suspension was obtained, which was stored at $-20^{\circ} \mathrm{C}$. in $1 \mathrm{ml}$. aliquots.

In each pair of experiments, atheromatous tissue was compared with normal from the same aorta, each patient acting as his own control.

THROMBOPLASTIN GENERATION TEST The method of Biggs and Douglas (1953) was used, with the following modification: $0.3 \mathrm{ml}$. of aortic homogenate, either normal or atheromatous, was substituted for the platelet component in the incubation mixture. A control experiment, using $0.85 \%$ saline solution instead of the homogenate, was also carried out.

UROKINASE SENSITIVITY TEST The method of McNicol and Douglas (1964) was used. To $0.1 \mathrm{ml}$. of pooled citrated human plasma was added $0.1 \mathrm{ml}$. of aortic homogenate, either normal or atheromatous. To this was added $160 \mu \mathrm{l}$. of urokinase (Leo) containing $500 \mathrm{u} . / \mathrm{ml}$. and the mixture clotted with $0.1 \mathrm{ml}$. thrombin. On incubation at $37^{\circ} \mathrm{C}$., times for complete clot lysis were recorded. A control, substituting $0.1 \mathrm{ml}$. saline instead of the homogenate, was carried out.

As there was a constant amount of plasminogen and fibrinogen in all the experiments, i.e., the concentration in the blank plasma, variations in lysis times reflect variations in total antifibrinolytic activity, i.e., a summation of antiactivator activity and antiplasmin. Results are expressed in lytic units which are reciprocals of lysis times, a lysis time of 10 minutes representing 1 lytic unit (Sherry, Lindemeyer, Fletcher, and Alkjaersig, 1959).

ONE-STAGE PROTHROMBIN TIMES These were estimated as described by Douglas (1962), modified by substituting $0 \cdot 1 \mathrm{ml}$. aortic homogenate, normal or atheromatous, for brain thromboplastin.

MODIFIED 'CHANDLER'S TUBE' TECHNIQUE This test (Chandler, 1958) was used for determining the effect of aortic tissue on platelet aggregation in vitro. The principle of the method is that blood or plasma is recalcified and rotated in a closed loop of transparent plastic tubing. After a variable time, usually eight to 12 minutes, platelet aggregation is seen as a 'snowstorm' effect. This is followed in 30 to 60 seconds by fibrin formation, the resulting clot resembling, with platelet head and fibrin tail, a thrombus formed in vivo.

The Chandler's tube system was used as modified by
Cunningham, McNicol, and Douglas (1965) with some further modifications.

1 Platelet aggregation by aortic homogenate Blood was collected by clean venepuncture using plastic syringes, and citrated by adding 9 volumes blood to 1 volume $3.8 \% \mathrm{w} / \mathrm{v}$ sodium citrate in a siliconized tube. Following centrifugation at $600 \mathrm{~g}$ for five minutes, the platelet-rich plasma was pipetted off: $10 \mathrm{ml}$. of plasma was placed in each of two Chandler's tubes, and diluted with $10 \mathrm{ml} .0 \cdot 85 \%$ saline. The tube was prepared from a 27.5 in. length of transparent vinyl tubing (Portland Plastics N/17) made into a closed loop by means of a nylon adaptor. One millilitre of aortic homogenate was added, atheromatous to one tube and normal to the other. Following recalcification with $0.6 \mathrm{ml}$. M/4 calcium chloride the two tubes were rotated simultaneously at 28.5 r.p.m. on the turntable of a blood cell suspension mixer at $37^{\circ} \mathrm{C}$. The times until platelet aggregation and fibrin clot formation were noted.

2 Platelet adhesion to aortic tissue This was estimated as follows. Two Chandler's tubes were prepared, each containing $8 \mathrm{ml}$. whole citrated blood and $10 \mathrm{ml} .0 \cdot 85 \%$ saline; to one was added pieces of whole normal aorta totalling $5 \mathrm{sq} . \mathrm{cm}$. in area, and to the other an equal amount of atheromatous aorta. Both tubes were rotated simultaneously at $37^{\circ} \mathrm{C}$. for 10 minutes. Platelet counts in the fluid from both tubes were carried out before and after rotation. The fall in platelet count during rotation represented the degree to which platelets had adhered to the tissue; or, under the stimulus of the tissue, had adhered to the wall of the tubing.

Plasminogen This was assayed by the method of Remmert and Cohen (1949) modified by Alkjaersig, Fletcher, and Sherry (1959). The method is described by $\mathrm{McNicol}$ and Douglas (1964).

Fibrin plate tests Primarily, these are a measure of plasminogen activator, and were carried out by the method of Nilsson and Olow (1962) as modified by McNicol and Douglas (1964).

\section{RESULTS}

THROMBOPLASTIN GENERATION TEST The mean values for 11 subjects of the percentage of thromboplastin generated in the incubation mixture are shown in Figure 1. Generation was accelerated and augmented by the atheromatous compared with the normal tissue: the difference was highly significant $(t=4 \cdot 73$, $\mathrm{p}<0.001$ ).

In a second series of observations, no correlation was found between the age of the patient and the thromboplastic activity of the aorta. For example, after six minutes' incubation the intrinsic thromboplastin generated in two young adults was $60 \%$ and $19 \%$, and in a stillborn infant it was $24 \%$.

ONE-STAGE PROTHROMBIN TIMES Results, expressed as mean values for the 11 subjects, are shown in Table I. There was no difference in activity between the normal and atheromatous aortic tissues. When 


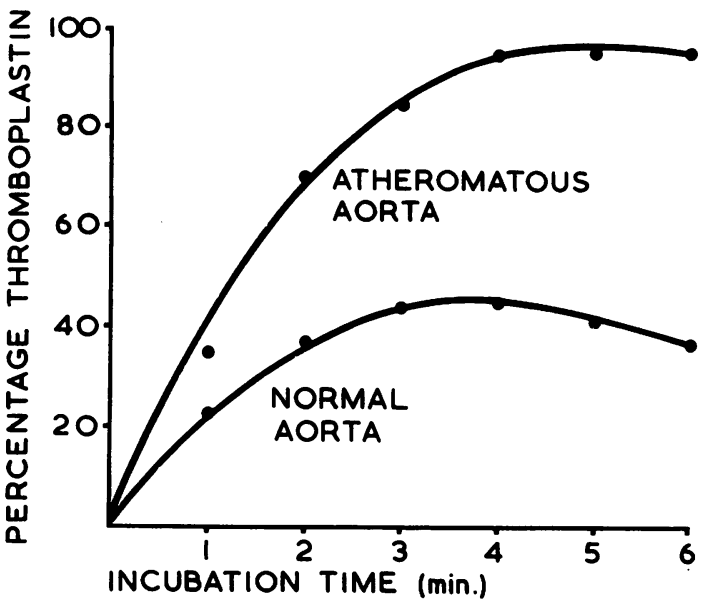

FIG. 1. Percentage of intrinsic prothrombin activator (thromboplastin) generated in the thromboplastin generation test by normal and atheromatous tissue.

standard brain thromboplastin was used, clotting times between 17 and 20 seconds were recorded.

PLATELET AGGREGATION IN CHANDLER'S TUBES INDUCED BY TISSUE HOMOGENATES The results, expressed as mean values for the 11 subjects, shown in Table I, indicate that no difference was present between normal and atheromatous tissue. The normal sequence of events seen in thrombus formation, that is, platelet aggregation followed by fibrin formation, occurred in the usual order, but the process was accelerated so that fibrin was formed five to 10 seconds after platelet aggregation, instead of after the normal delay of 30 to 45 seconds.

\section{TABLE I}

THE EFFECT OF NORMAL AND ATHEROMATOUS AORTIC HOMOGENATE IN ONE-STAGE PROTHROMBIN TEST, CHANDLER'S TUBE TEST, AND UROKINASE SENSITIVITY TEST

\begin{tabular}{lccc} 
& Normal & Atheromatous & Control $^{2}$ \\
\hline $\begin{array}{l}\text { One-stage prothrombin } \\
\text { test (sec.) }\end{array}$ & $30 \cdot 3 \pm 6 \cdot 5^{1}$ & $31 \cdot 1 \pm 5 \cdot 1$ & 125 \\
$\begin{array}{l}\text { Chandler's tube clotting } \\
\text { times (sec.) }\end{array}$ & $167 \pm 18$ & $160 \pm 15$ & 600 \\
$\begin{array}{l}\text { Urokinase sensitivity } \\
\text { (lytic units) }\end{array}$ & $\begin{array}{l}0.9 \pm 0 \cdot 3 \\
\text { I'Mean values and standard deviations are shown. }\end{array}$ & $1 \cdot 0 \pm 0 \cdot 2$ & $0 \cdot 7 \pm 0 \cdot 2$ \\
$\begin{array}{l}\text { 'In control experiments normal saline was substituted for the tissue } \\
\text { homogenate. }\end{array}$
\end{tabular}

UROKINASE SENSITIVITY TEST The results, seen in Table I, show that no significant difference in activity was present between the atheromatous and normal aortic tissue. But the difference between the atheromatous tissue, mean 1 lytic unit, and the saline control, mean 0.7 lytic units, was significant $(\mathrm{t}=2 \cdot 26, \mathrm{p}<0 \cdot 05)$.

PLASMINOGEN ASSAY Plasminogen assays of bot normal and atheromatous tissue showed that no plasminogen was present in either type of tissue.

Plasminogen activator assays of normal and atheromatous tissue failed to reveal activity.

PLATELET ADHESION The fall in platelet count expressed as a percentage of the initial plateles count, following rotation of whole citrated bloof with either normal aorta or ulcerated atheromatous plaques in a Chandler's tube is shown in Figure 29 The ulcerated atheromatous plaques caused $\widetilde{a}$ greater mean fall in platelet count, $49.8 \%$ than die normal aorta, mean $29.9 \%$, for 20 observations The difference is significant $(\mathrm{t}=3 \cdot 11, \mathrm{p}<0.01)$.

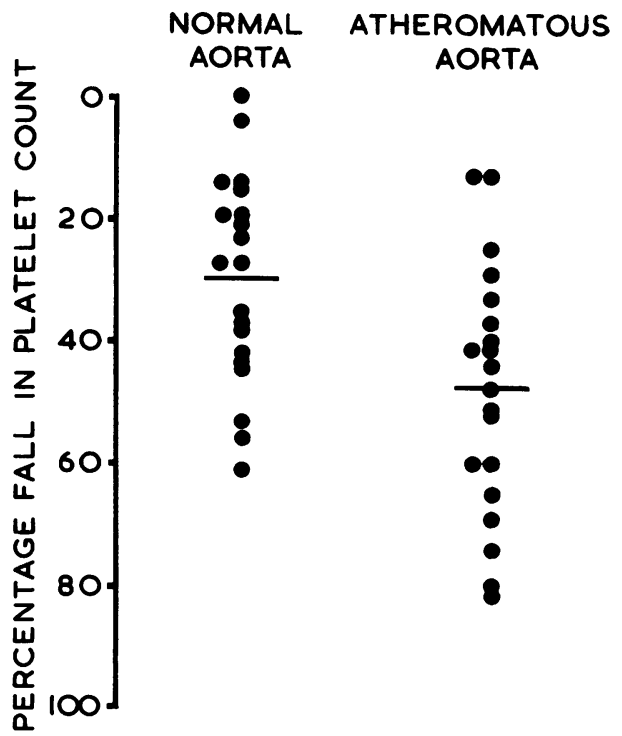

FIG. 2. Percentage fall in platelet count caused by normat

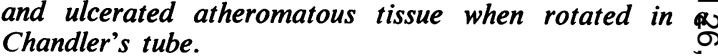

When non-ulcerated atheromatous plaques werê rotated, the fall in platelet count did not diffee significantly from that obtained with normal aortace

Rotation per se in the Chandler's tube of whole citrated blood caused a fall in platelet count of less than $10 \%$ in each of two experiments.

\section{DISCUSSION}

The present studies demonstrate that, although there is no difference in tissue thromboplastin production 
between normal and atheromatous aortic tissue, the atheromatous portions of aorta promote significantly increased generation of intrinsic prothrombin activator compared with normal artery.

Duguid (1946) showed that atheromatous plaques could be formed by the organization of mural thrombi, and more recently it has been confirmed that intravascular thrombi are composed mainly of platelets, leucocytes, aod fibrin (Poole, 1961). The contribution of the atheromatous lesion to their formation is not known, although its importance is shown by the fact that intravascular thrombosis almost always occurs on pre-existing atheromatous plaques (Crawford, Dexter, and Teare, 1961). Although eddying within the blood stream caused by the stenotic lesion may be partly responsible (Mustard, Rowsell, and Murphy, 1964) the demonstration by Duguid (1955) that atheromatous plaques may be formed by recurrent deposition of mural thrombus with subsequent endothelialization suggests that once an initial plaque has been formed there is a factor within it which predisposes to continued thrombus formation at the same site.

The increased generation of intrinsic prothrombin activator by atheromatous vessel suggests a possible mechanism by which, in its vicinity, there may be increased fibrin formation leading to the deposition of mural thrombi and growth of the atheromatous plaque. The responsible factor within the vessel has not been identified, but as the active platelet component in the thromboplastin generation test is probably a phospholipid (Troup, Reed, Marinetti, and Swisher, 1960; Alkjaersig, Abe, and Seegers, 1955 ) it is possible that the atheromatous lesion acts by virtue of its increased phospholipid content. It appears that a combination of phospholipids may be necessary for maximal generation of intrinsic thromboplastin (Daemen, van Arkel, Hart, van der Drift, and van Deenen, 1965), and it is probable that the clot-promoting activity of phospholipids is related to the surface charge of the lipid micelles.

FIBRINOLYSIS No significant difference was noted when the antifibrinolytic activity of normal and atheromatous aorta was compared in the urokinase sensitivity test, suggesting that atheromatous aorta does not potentiate intravascular thrombosis by local reduction of thrombolysis.

Although in the present study no fibrinolytic activity was found in normal or atheromatous aortic tissue, others (Todd, 1964; Warren, 1964) have reported that arterial endothelium does contain significant amounts of activator or proactivator. Astrup et al. (1959) failed to find activator in most arterial medial or intimal layers, although Kowalski, Kopec, Latallo, Roszkowski, and Sendys (1958) demonstrated a plasminogen-like substance in arterial wall. It is generally considered that plasma activator is the main agent in mediating thrombolysis (Sherry et al., 1959). Kwaan and McFadzean (1956) suggested that its source is in the venous rather than the arterial endothelium, and although the total failure to find activity in our experiments may be partly due to the lability of plasminogen activator, the negative findings support the view that the endothelium of the large vessels on the arterial side of the circulation is not a major source of plasminogen activator.

It is known that platelets exert an antiplasmin effect (Johnson and Schneider, 1953) which may prolong the survival of thrombi. Similarly it was considered that atheromatous vessels, rich in phospholipid, might exert a similar anti-thrombolytic effect; the negative results of the urokinase sensitivity test do not support this hypothesis.

PLATELET AGGREGATION When pieces of whole aorta were rotated with citrated blood in a Chandler's tube, ulcerated atheromatous plaques caused significantly greater aggregation of platelets than did normal aorta, as measured by the fall in platelet count following rotation. As no difference was seen when normal aorta was compared with non-ulcerated atheromatous plaques, the results suggest that ulcerated endothelial surface has a direct effect in increasing platelet aggregation not possessed by intact intima.

It has become increasingly clear from studies in vitro and in vivo that platelets play an important, if not a key, role in initiating intravascular thrombosis (Poole and French, 1961; Hellem, 1960; Russell, 1961). The stimulus causing platelets to adhere to vascular intima must be either within the circulation or the vessel wall or both (Pickering, 1964). There is evidence from animal experiments (Cotton, Harwood, and Wartman, 1961) that platelets adhere to injurcd but not to intact endothelium. Within the arterial wall there are substances capable of initiating platelet aggregation, identified as collagen or a closely related compound (Hugues, 1960; Zucker and Borrelli, 1962), and adenosine diphosphate (Mitchell and Sharp, 1964), although Hellem (1960) did not find platelet-aggregating activity in bovine aorta. Other factors operating might be the mechanical effect of platelet trapping by the crevices of the ulcerated plaque, or alteration of the electrical charge of the intima (Sawyer and Pate, 1953). Frequently there is an accumulation of red cell debris mixed with pultaceous lipid at the base of an ulcerated plaque, and the adenosine diphosphate content of this may be sufficient to initiate platelet aggregation. 
The finding of similar platelet aggregation when homogenates of normal and atheromatous aorta were added to platelet-rich plasma in a Chandler's tube suggests that the ulcerated plaques increase platelet aggregation by a surface phenomenon which is destroyed when the tissue is homogenized.

The relation between platelet aggregation, fibrin formation, and fibrinolysis is complex, for, although fibrin formation does not initiate platelet aggregation, it may be responsible for the persistence of platelet thrombi once they are formed. McNicol, Bain, Walker, Rifkind, and Douglas (1965) have shown that the platelet-rich head of a Chandler thrombus can be reduced to fragments by the action of streptokinase, a fibrinolytic activator. As atheromatous tissues possess, in certain circumstances, enhanced ability to induce fibrin formation and platelet adhesion compared with normal tissue, it would appear that once an atheromatous plaque has been induced, its further growth may be a selfsustaining process.

We are grateful to Professor E. M. McGirr and Dr. E. G. Oastler for their interest in this work. Thanks are due to the Medical Research Council for financial support.

\section{REFERENCES}

Alkjaersig, N., Abe, T., and Seegers, W. H. (1955). Amer. J. Physiol., $181,304$.

Fletcher, A. P., and Sherry, S. (1959). J. clin. Invest., 38, 1086 Astrup, T., Albrechtsen, O. K., Claasens, M., and Rasmussen, J. (1959). Circulat. Res., 7, 969.
Biggs, R., and Douglas, A. S. (1953). J. clin. Path., 6, 23.

Chandler, A. B. (1958). Lab. Invest., 7, 110.

Cotton, R. E., Harwood, T. R., and Wartman, W. B. (1961). J. Pat Bact., 81, 175.

Crawford, T., Dexter, D., and Teare, R. D. (1961). Lancet, 1, 181.

Cunningham, G. M., McNicol, G. P., and Douglas, A. S. (1965 Ibid., 1, 729.

Daemen, F. J. M., van Arkel, C., Hart, H., van der Drift, C., arie van Deenen, L. L. M. (1965). Thrombos. Diathes. haemorro (Stuttg.), 13, 194.

Donner, L. (1962). J. Atheroscler. Res., 2, 88.

Douglas, A. S. (1962). In Anticoagulant Therapy, p. 279. Blackweff?, Oxford.

Duguid, J. B. (1946). J. Path. Bact., 58, 207.

(1955). Brit. med. Bull., 11, 36.

Hellem, A. J. (1960). Scand. J. clin. Lab. Invest., 12, suppl. 51.

Hugues, J. (1960). C.R. Soc. Biol. (Paris), 154, 866.

Johnson, S. A., and Schneider, C. L. (1953). Science, 117, 229.

Kowalski, E., Kopec, M., Latallo, Z., Roszkowski, S., and Sendys, (1958). Blood, 13, 436.

Kwaan, H. C., and McFadzean, A. J. S. (1956). Clin. Sci., 15, 245. N

McNicol, G. P., and Douglas, A. S. (1964). In Recent Advances $\overrightarrow{d y}$ Clinical Pathology, Series IV, pp. 203-205. Churchill, Londof?

—, Bain, W. H., Walker, F., Rifkind, B. M., and Douglas, A. Q (1965). Lancet, 1, 838.

Mitchell, J. R. A., and Sharp. A. A. (1964). Brit. J. Haemat., 10, 78.Mustard, J. F., Rowsell, H. C., and Murphy, E. A. (1964). Amer. $\mathbb{Z}$ med. Sci., 248, 469.

Nilsson, I. M., and Olow, B. (1962). Acta chir. scand., 123, 247.

Pickering, G. W. (1964). Brit. med. J., 1, 517.

Poole, J. C. F., and French, J. E. (1961). J. Atheroscler. Res., 1, 25t

Remmert, L. F., and Cohen, P. P. (1949). J. biol. Chem., 181, 431. O

Russell, R. W. R. (1961). Lancet, 2, 1422.

Sawyer, P. N., and Pate, J. W. (1953). Amer. J. Physiol., 175, 113.

Sherry, S., Lindemeyer, R. I., Fletcher, A. P., and Alkjaersig, N. (1958 J. clin. Invest., 38, 810.

Stevenson, T. D., Schrodt, G. R., and Reed, L. M. (1961). Amer. med. Sci., 241, 632.

Todd, A. S. (1964). Brit. med. Bull., 20, 210.

Troup, S. B., Reed, C. F., Marinetti, G. V., and Swisher, S. N. (19600) J. clin. Invest., 39, 342.

Warren, B. A. (1964). Brit. med. Bull., 20, 213.

Zucker, M. B., and Borrelli, J. (1962). Proc. Soc. exp. Biol. (N. Y.), 10 779. 